\title{
SPACE-TIME COMPRESSION AND HYPERLOCALISATION: THE NEW FLÂNEURS
}

\author{
Ivone Neiva Santos \& José Azevedo
}

\begin{abstract}
The experience of sensations such as time acceleration and space elimination has become common in modern life, which is increasingly organised in tune with the "real time" imposed by digital media. Throughout this article and starting with the concept of "time compression" presented by David Harvey (1999), the authors contrast technological determinism with other perspectives that suggest there is a dialogue-based relationship between technology and society. The text discusses notions such as deterritorialisation and detemporalisation that make it possible to understand the emergence of a fragmented and timeless data space, which corresponds to a "new geography", in which it is no longer possible to establish a clear boundary between the physical and the digital world. The text is theoretically underpinned by the concept of the $c y$ berflâneur, exploring the similarities with the $19^{\text {th }}$ century flâneur described by Baudelaire (1996). Analysis of a set of artistic and experimental interventions addressing issues such as hyperlocalisation or ubiquity and pervasiveness enables us to use the character of the cyberflaneur in a twofold sense - as a sign of technical acceleration and also as a symbol of resistance to such acceleration. The authors conclude that the exponential evolution and increasing "naturalisation" of technology obligates us to consider its determining role in social dynamics, namely by transforming our relationship with the dimensions of space and time.
\end{abstract}

KEYWORDS

Sentient city; space-time compression; power-chronography; augmented space, cyberflâneur

\section{COMPRESSÃO DO ESPAÇO-TEMPO E HIPERLOCALIZAÇÃO: OS NOVOS FLÂNEURS}

\begin{abstract}
Resumo
A experiência de sensações tais como a de aceleração do tempo ou de eliminação do espaço vulgarizou-se na vida moderna cada vez mais organizada segundo o ritmo do "tempo real", instituído pelos média digitais. Neste artigo, partindo do conceito de compressão espaço-tempo de Harvey (1999), confrontamos perspetivas situadas nas correntes do determinismo tecnológico com outras que defendem a relação dialógica entre tecnologia e sociedade. Abordam-se noções como as de desterritorialização e destemporalização que permitem compreender o surgimento de um espaço de dados fragmentado e intemporal, correspondendo a uma "nova geografia", na qual já não é possível estabelecer uma fronteira clara entre o mundo físico e o digital. O texto estrutura-se tendo como suporte teórico o conceito de flâneur ciberespacial, explorando as semelhanças com o flâneur novecentista, tal como descrito por Baudelaire. A análise de um conjunto de intervenções artísticas e experimentais centradas sobre questões como a hiperlocalização ou a ubiquidade e a pervasividade permite-nos recorrer a esta figura do flâneur ciberespacial num duplo sentido, como sinal da tendência para a aceleração técnica, mas também como símbolo da força de resistência a essa mesma aceleração. Conclui-se que a evolução exponencial e a crescente "naturalização" da tecnologia nos obrigam a considerar o seu papel determinante nas dinâmicas sociais, designadamente, a partir da transformação da nossa relação com as dimensões do espaço e do tempo.
\end{abstract}




\section{INTRODUCTION}

This article seeks to observe the critical role played by digital media in challenging historically significant concepts of time and space, and thereby changing the way that people shape their identities and broadening the scope of physical and psychological mobility in today's globalised world. Increasingly enmeshed within modern life, through wireless networks or surveillance systems, the ubiquity of digital media has mushroomed, making it increasingly difficult to distinguish between the social, technological, spatial or temporal.

From this standpoint, the text questions whether the concepts of deterritorialisation and detemporalisation enable us to understand the uses of space and time in this new context, characterised by acceleration and fragmentation, and also by the emergence of a new timeless, continuous and pervasive data-space.

The flâneur character proposed by Baudelaire (1996) and Benjamin (2000), in the context of the modernisation and development of cities associated with industrialisation, was further developed by authors such as André Lemos (2009), Kathryn Kramer and John R. Short (2011), with regard to technological evolution and globalisation. The invocation of that character is framed within this strategy of summarising the key issues of the debate, in which we identify features of this new context which we can relate to with a certain flânerie. This is required because we are dealing with a context that favours the definition of personal itineraries and the maintenance of fluid relations with the different spatio-temporal contexts experienced by the citizen/cybernaut. Likewise, it fuels the resistance movement against "modernity" - which now incorporates the monitoring and control systems fostered by the technological development encouraged by globalisation.

This article is organised as follows: first, the authors present the theoretical approach which states that technological development increasingly determines the way we experience and understand space and time, relating this approach with the concept of space-time compression. Then they address: a) the perspective that gives technology a purely instrumental role, finding in social dynamics the raison d'être for the acceleration of time and elimination of space that characterise modernity; b) the specific role of digital media in this transformation; c) the suitability of the character of the flâneur for analysis of this new spatio-temporal reality. Finally, they summarise the main ideas discussed throughout the article.

\section{SPACE-TIME COMPRESSION AND TECHNOLOGICAL DEVELOPMENT}

The relationship between technological evolution and the perception and experience of space-time has been object of significantly different readings. Harold Innis (1950) is a particularly relevant name among authors who have identified a univocal trend towards 
the acceleration associated with technological development. Based on his studies about political economy, the author considers that the means of transportation play a decisive role in historical development, with profound implications on the way that societies are structured and organised (Subtil, 2014). For Innis (quoted in Subtil, 2014), technology is the means through which civilisations have expanded and established relationships with each other. As Subtil (2014) refers, Innis argues that each historical period is characterised by a dominant media and, consequently, this domination produces a "bias" or orientation towards either time or space. Time-oriented societies are dominated by media that are heavy, difficult-to-transport, and also difficult to destroy and, for that reason endure over time - such as oral traditions and cave paintings. They are media adapted to a limited human capacity for memorising, and make it possible to preserve knowledge over time. In turn, the societies that Innis identifies as having "space bias" are principally oriented towards the future, and prefer light and perishable media with a large capacity for storing information (such as newspapers or television). Western modern societies would thus be mainly shaped by a space-bias and would be oriented towards communicating at a distance.

Paul Virilio (2000), Anthony Giddens (2002) and Manuel Castells (2010) also highlight the role of transport and communication technologies, as inductors of physical and informational speed, through alteration of our perception of time and space. Marshall McLuhan (1969), who taught Innis and had a profound influence on him, concurs with this perspective, and argues that each new media propitiates a change of scale, rhythm or pattern in human activity.

According to Virilio (2000), the great historical revolutions are, above all, revolutions of speed. By allowing greater speed, each new vehicle produces new forms of transport and communication, each corresponding to a "dromocratic" revolution'. Virilio argues that the most important characteristic of the industrial revolution, made possible by the emergence of the steam engine, was the transport revolution, which he calls a space-time revolution.

Virilio also names another transforming revolution in the $19^{\text {th }}$ century - the emergence of the "aesthetic of disappearance" (photography and cinema) that follows the "aesthetics of appearance" (painting and sculpture). In his view, the speed of recording images in instant photography and the speed of projecting images in film (24 frames per second), underpinned by retinal persistence, made it possible to evolve "from the persistence of a material substrate - the marble or the painter's canvas - to the cognitive persistence of vision" (Virilio, 2000, p. 24). Hence, cinema is "capable of providing spectators, in every fraction of a second, that unknown sensation of ubiquity, in a fourth dimension, suppressing space and time" (Virilio 1989, p. 61).

According to Virilio, cinema would later be "replaced" by the automobile, corresponding to his idea that our entire life passes through "accelerated travel prostheses of which we are not aware" (Virilio, 1989, p. 68), including the train, the automobile, the television and the computer. Virilio believes that speed has taken root in the lives of

\footnotetext{
' From the Greek dromos, meaning "racetrack".
} 
individuals and societies, continually changing our values and perceptions. He argues that it is with Albert Einstein and his relativistic conception of the world that a new reality was instituted, in which speed is superimposed over time and space, just as light overcomes matter (Virilio, 1989). If we attain the speed of light, we will replace historical time, the domain of History, and physical space, the domain of Geography, by a unique present, without a human dimension, which, according to Virilio, paradoxically reminds us of the "great imprisonment" identified by Michel Foucault (1978). From this perspective, instead of being confined within a prison, we would be locked within "the speed and inanity of any displacement" (Virilio, 2000, p. 61). Virilio is concerned, therefore, with the ubiquity and instantaneousness provided by digital media. This is because, as he states, although all History happens in a local time, the application of real time, which is the rhythm of the immediacy of response made possible by digital technology, has no relation to historical time. Daily experience would thus be reduced to the immediacy of a continuous present (Virilio, 2000).

This reading may be related to the concept of space-time compression, formulated by David Harvey (1999). In Harvey's perspective, space and time have been "commodified". Homogenised, on the one hand, and fragmented, on the other, they have become tradable goods, constituting a mainstay of capitalism and globalisation, contributing to the increasing irrelevance of the nation state in favour of the world financial economy (Löw, 2008). Harvey's concept implies a process that changes the relationship between time and space, in particular through technological innovation and globalisation. According to Harvey, compression is linked to the increase in speed associated with the development of means of transportation and communication, because our experience of space depends on a large extent on the time it takes to travel through it (Rosa, 2013). Reflecting on the very nature of space, Harvey (2015) proposes three dimensions of analysis: absolute space, relative space, and relational space.

Absolute (Cartesian-Newtonian) space is a fixed and independent entity, unambiguous, and therefore capable of being observed and classified. Socially, it corresponds to clearly demarcated territorial entities, such as States or private property. For the author, the production of "spaces", and their respective organisation and distribution, is a central feature of capitalism. Relative space (as postulated by Einstein) already corresponds to the relationship between objects, and therefore depends on the existence of objects and also the point of view of the observer. This conception of space is inseparable from time - the relative space-time of the speed of light - and from factors that interfere in this relationship (such as social and technological evolution). Harvey (2015) notes, however, that it is not possible to understand different realities from the same space-time framework ${ }^{2}$. Therefore, drawing on Leibniz', he also proposes the concept of relational space, which exists only insofar as it is part of the process that defines it. For Harvey,

\footnotetext{
${ }^{2}$ The author refers to financial and energy flows in ecological processes as examples of incompatible spatiotemporalities (Harvey, 2015).

${ }^{3}$ For theological reasons, Leibniz challenged Newton's absolute time formulation, which implied that God himself would be "inside" space, which was incompatible with the vision of God as the creator of space and time (Harvey, 2015)
} 
"processes do not occur in space, but [rather] define [their] own spatial picture" (Harvey, 2015 , p. 130). For this reason, space is also inseparable from time, and the focus is placed on the relationship between the two. Although relational space-time suggests difficulties of measurement, the author considers that the three concepts are valid, depending on the applicability of the respective objectives. Absolute space may apply when defining boundaries or properties, but not, for example, when considering the relative positions of subjects, or each person's experiences. Equally relevant in this context, Harvey highlights the spatialisation of thought, expressed through the use of spatial metaphors in literature and the arts, such as the distinction between real space and virtual space, wherein the latter is inhabited by the "intangible images and illusions that form the heart of all aesthetic practices" (Langer quoted in Harvey, 2015, p. 135).

According to Harvey, the distinction made by Ernst Cassirer (quoted in Harvey, 2015, p. 136) between organic, perceptual and symbolic spaces (wherein the latter is abstract, associated with geometry and artistic interpretations), would have underpinned another classification, proposed by Henri Lefebvre (quoted in Harvey, 2015, p. 136). This classification combines experienced (material) space, conceptualised space (how it is represented) and lived space (of emotions and meanings). Harvey (2015) articulates his classification and that of Lefebvre with three key concepts proposed by Karl Marx (1887): use value, exchange value and value. Use value is inscribed within the domain of absolute space and time. Exchange value implies a relationship, the movement of goods, capital, people, which is inscribed within relative space-time. According to Marx (quoted in Harvey, 2015), exchange would constantly change the space-time coordinates, since it is inscribed within a continuous movement. With the emergence of money, value, the movement of circulation becomes even more fluid, already inscribed within relational space-time.

The control of time and space made possible by money would be the mainstay of capitalism. Harvey creates a revealing matrix, demonstrating that which occurs in each of the considered dimensions only makes sense in dialectical terms, thereby justifying his relational approach ${ }^{4}$. Giddens also proposes an approach that is inscribed within this "relational" logic, when he defines space by its social function and not so much by its materiality (Löw, 2008). For Giddens, the process he calls "regionalisation" consists of the division of space and time into regions associated with specific social practices. Regarding technological development, Giddens (2002) proposes the concept of spacetime distanciation to refer to the fact that social events appear to be disconnected from the space-time matrix. Castells (2010) also describes the systematic disturbance in the sequential order of social practices as the dominant time expression in network-based societies, where the temporal experience is diluted in "timeless cyberspace" (Castells quoted in Sora, Jordà \& Codina, 2017, p. 197). This concept refers to the Internet's capacity for constant reconfiguration, since it characterised by the absence of time and space limits. For the author this reconfiguration can take the form of compression or introduce discontinuity in the sequence. According to Hartmut Rosa (2013), given the almost unlimited speed and capacity of digital technology, time would be losing its linear

\footnotetext{
${ }^{4}$ Harvey presents "Ground Zero" in Manhattan as an example of this "dialectical tension" $(2015$, p. 141)
} 
character as the chronological sequence of events seems to dissolve progressively. While compressing time, it would cause time itself to disappear, which would be equivalent to eternity (Rosa, 2013). Following the same line of thought, Robert Hassan and Ronald E. Purser (quoted in Sora et al., 2017, p. 197) consider asynchrony as the real temporality, arguing that the Internet enables social actors to become involved in communications in different spaces and times, regardless of the actual local time. Thus, time would be simultaneously homogeneous and almost infinitely fragmented in the multiple synchronous and asynchronous temporalities that coexist in the network. The experience of modernity, for these authors, would thus be not so much a question of acceleration, as the simultaneity of different times, wherein it is certain that without the speed or immediacy provided by technological development such simultaneity would be impossible.

In short, these perspectives converge in the assignment of a fundamental role to technological development in the transformation of how we perceive and experience space and time and the relationship between them. The systematic increase of speed obtained through the development of means of transport and of communication, up to the limit that digital technology currently provides us of real-time access to any place in the world, would result in the changing of space and time coordinates and the need to adopt new conceptual approaches and new classifications that may enable us to understand this new spatiotemporal reality. Other authors, as we shall see below, attribute a less determinant role to technological evolution.

\section{SPACE-TIME COMPRESSION AND SOCIAL CHANGE}

Other authors ascribe less "prominence" to technology, placing it in a wider set of social dynamics. Rosa (2013) argues that the principle of acceleration forms an integral part of the culture of modernity, prior to its technological implementation. Although he draws close to Virilio's perspective, in identifying two main waves of acceleration in the history of Western civilisation (the first associated with the technological innovations engendered by the Industrial Revolution and the second to the digital revolution and globalisation), he believes that a process of permanent transformation cannot be understood deterministically, on the basis of technological acceleration. Instead it is a symptom of the acceleration of social change. Following the same line of reasoning, Sarah Sharma (2014) classifies the approach of those she calls "speed theorists" as being simplistic. In her opinion, although the discourse about speed has become hegemonic, it does not reflect the complexity and the different rhythms that underpin social experience. Sharma contests that speed should be understood as a homogeneous trend associated to a certain epoch or dominant technology. She sees it rather as a mechanism of social differentiation, framed by global contemporary capitalism. To express her vision, she proposes the concept of "power-chronography"s, according to which certain groups are more responsible than others for time-space compression, since they make use of this compression, turning it into an advantage.

\footnotetext{
${ }^{5}$ From Massey's concept of "power geometry" (1991).
} 
In this regard, Sharma (2014) explores the paradoxes of the figure of the corporate warrior who is simultaneously privileged because he stands at the forefront of communication and capital networks, and yet is vulnerable as a victim, for example, of jet lag or stress or dependent on the availability of others whose time is less valued (such as taxi drivers or hotel staff, for example). In short, for Sharma, it is not speed that produces inequality, but its explanatory, normalising power, as if it were a uniform experience in the contemporary moment that values the time of some people to the detriment of others and excludes those who experience time in a different way.

Following this rationale, the author criticises the strategies of "ideological" deceleration, such as the slow movements, noting that the capacity to slow down is itself a form of privilege that, on the other hand, presupposes an individualistic and depoliticised positioning. As an alternative, the author proposes the creation of "public times", a concept thought to complement the notion of "public space" and thus drawing attention to the unequal nature of these "public" spheres. In the same sense, Lemos (2009) considers that although mobility may be "enlarged" in today's societies, it is not neutral. Physical mobility, due to the most advanced means of transportation, and informational mobility, due to the wireless internet and portable devices, vary correlatively according to the position that individuals and groups occupy in power structures. Thus, those who can more easily move through cyberspace are also those who have greater autonomy in terms of physical mobility.

Doreen Massey (1991) questioned to what extent the relative mobility of some and their power over the mobility and communication of others increases the spatial imprisonment of the latter. She proposed the concept of power geometry, noting that different social groups are positioned in very different places in the flows and interactions associated to globalisation, wherein some are free to move, while others remain "imprisoned" in the same place and, therefore, tend to be more defensive about it ${ }^{6}$. This new context implies that what we mean when we talk about "places" is less clear, and the way that we relate to them is more complex. Massey argues that the specificity of a place is built from a constellation of social relations and carries multiple identities. She therefore rejects the identification of a place with a specific community. A community can exist in different locations simultaneously and is itself heterogeneous, since people occupy different positions therein.

The idea of spaces inhabited by homogeneous communities that persist in social imagery is contradicted by the current tendency towards fragmentation and spatial rupture. Nevertheless, Massey also criticises the idea that the quest for a sense of place is necessarily reactionary. The sense of rooting can be a source of positive identity if it is defined not through opposition to the exterior, but in its relation to it, moving away the idea of vulnerability of the local in relation to the global. Massey seeks to "pacify" the relationship between the local and the global, defending what she calls "a progressive sense of place" and conceiving it as a heterogeneous, dynamic, borderless construction, crossed by networks that extend beyond the geographical scale.

\footnotetext{
${ }^{6}$ According to Harvey (quoted in Antonsich, 2011), this would be the paradox of globalisation which, by making places seem less stable and secure, would make people more attached to them.
} 
Deterritorialisation of the social organisation is a thesis shared by a growing number of authors. Ash Amin (2002) even questions the extent to which the separation between place (viewed as close and intimate) and space (perceived as distant and intrusive) continues to make sense when the scalar design of the territory is altered as a result of globalisation. The mobility and interactivity engendered by this new communicational context interfere with territorial forms of social organisation, creating new relations between space and place. For Amin the new spatialities proposed by globalisation should be read as networks beyond any geographical scale (2002).

This is not a question of an alteration in power relations between spatial scales, but rather of deterritorialisation or reterritorialisation of social organisation. It is a question of recognising the growing influence of non-territorial practices and configurations in spatial policies themselves. As Paul Dourish and Genevieve Bell (2007) point out, infrastructures and widespread computing can reconfigure the relationship between the local and the global. From this perspective, the city would no longer be the site of politics of place, but rather of plural politics and multiple spatialities.

\section{SPACE-TIME (DE)COMPRESSION AND DIGITAL TECHNOLOGY}

Amin's proposal (2002) seems to correspond to the scenario resulting from the evolution of digital media that increasingly permeates all dimensions of daily life. Gere (2008) points out in fact that the distribution of broadband content and wireless networks have massively increased the way that digital technology penetrates our daily lives. This omnipresence, which Mark Weiser called "ubiquitous computing" (quoted in Dourish \& Bell, 2007) derives from the existence of computer interactions in every location. The growth of surveillance systems and the "internet of things", with devices that can communicate between each other and mutually coordinate their actions are expressions of this expansion (p.1).

Whereas on the one hand, media are described as sources of suspension and instantaneity, due to the acceleration they enhance, on the other hand they are also producers of material and symbolic time and space (Parmett, 2017). In this regard, and invoking the "end of geography", Stephen Graham (1998), like Harvey (2015), has drawn attention to the use of geographic metaphors, such as cyberspace or site, pointing out the effects of their use (with reference to something that is nothing else than a network of electronic signals) in the construction of new systems that become viewable and territorial. These metaphors would then be ideological constructs, also containing normative ideas about how technology should relate to society?. Studying this relationship, Graham (1998) identified three main trends: "substitution and transcendence", "co-evolution" and "recombination".

The first tendency ("substitution and transcendence") is framed by technological determinism, which, according to the author, includes two visions of the future. In one,

7 The use of expressions such as "shock" and "wave" (by Alvin Toffler) or concepts such as "information society" or "information age" to represent the very nature of present-day society are other examples (Graham 1998). 
relations based on proximity will be replaced by digital networks, liberating capitalist society from its spatial and temporal constraints; in the other, immersive virtual environments will emerge that "allow the immersive qualities of the geographical place to be transmitted remotely" (Graham, 1998, p. 168) enabling people to live remotely and instantly interact with entities previously only accessible in a physical location.

In this regard, Amin (2002) uses Jan Aart Scholte's expression "borderless world" (p. 386), in the same sense that Castells spoke about "timeless cyberspace". This perspective can be understood as utopian or dystopic. Paul Virilio (2000) holds a critical view, affirming that when the speed of light is reached, space and time are replaced by a unique present, which "imprisons" us, rendering useless any displacement. Yet, cyber-gurus such as Bill Gates and Nicholas Negroponte welcome the idea that the 3D environments provided by the combination of virtual reality and broadband can, by their verisimilitude, replace and make it unnecessary to travel to real places. 3D environments would be an alternative territory without the limitations of physical spaces - a technological utopia closely related to the ideology of progress typical of modern capitalist societies (Graham, 1998).

The second tendency ("co-evolution") defends that virtual space does not replace but incorporates reality within it, and evolves in articulation with it. Technology is seen in the broader picture of the struggle, always asymmetrical, for power, namely regarding the control of space and distance. From this perspective, technology penetrates the "real" spatial organisation, rendering it faster and more efficient, but cities still exist and maintain their dominion, incorporating technology, and the new possibilities that it offers, within their practices. On the one hand, physical places are progressively incorporated into a powerful network of transactions. On the other hand, this power depends on territorially interconnected communication and transport infrastructures (Harvey quoted in Parmett, 2017).

Staple (quoted in Graham, 1998, p. 175) identifies the emergence of a new tribalism made possible by digital networks, which, while they enable space and time to be compressed, also support a fragmented logic of differentiation. In this way, they provoke a "geographical explosion of space" (Graham, 1998, p. 174), since, instead of bringing everyone together in a single cyberspace, they deepen the relationship and commitment of different individuals and groups with specific places (material or virtual). The studies related to diasporic communities or ethnic minorities conducted by Kim (2016) and Heyd and Honkanen (2015) corroborate this perspective.

The third tendency identified by Graham - "recombination" - is based on the ActorNetwork Theory, which in the 1990 s already identified an increasing difficulty in separating the "social" from the "spatial" and "technological", arguing that the notion of the network frees us from the "tyranny of geographers" (Latour, 1996, p. 371) in the definition of space. According to this theory, technology is simultaneously constituted by technical elements and by social elements and processes that are difficult to analyse autonomously (Latour, 1996). Through technology, space life would be continually recombined into new arrangements of space and time, provisional and "localised", that cannot be 
generalised. From this perspective, the boundaries that separate the human being from the machine are porous, permeable and "cyborgian" (Graham, 1998, p. 178).

Cyberspace produces a multiple, fragmented network of infrastructures and relationships, through which new spatiotemporal configurations are continuously created. For example, it brings certain geographically distant places closer together, while distancing others that are physically closer, or establishes fluid, interactive and individualised connections with places (Georgalou, 2015). In this manner, technology, while transforming the culture of specific spaces, also assumes itself as a place of cultural production (Dourish \& Bell, 2007).

Lev Manovich (2006) looked at the way that people live in space when it is flooded with multimedia information, for example in shopping malls or airports. The author proposes the concept of "augmented space" 8 to describe the overloaded information space, usually in a multimedia format. He highlights the fact that the omnipresence of cyberspace has become the norm in the $21^{\text {st }}$ century, wherein physical space has been invaded by digital information, ranging from the ubiquity of electronic and mobile surveillance to publicly located computer/video displays, or the possibility of remotely accessing varied information via our mobile phones. The interconnection between these dimensions, according to Manovich, creates a continuous "dataspace" that extends and fills the entire physical spaces. Therefore, the space of the digital age is no longer geometric and stable, but open, changeable and complete with variable contours. This trend fits in with the new paradigm described by Nadav Hochman and Lev Manovich (2013), in which it is assumed that digital media cease to act as platforms, and instead become data aggregators, open to manipulation and reconfiguration. This is an environment which each person can explore, no longer in function of hierarchies, but rather in terms of relationships and sequences, "while moving from the singular to the plural, from the close to the distant" (Hochman \& Manovich, 2013, p. 37), thus breaking physical and virtual boundaries. This evolution can incorporate positive changes, such as access to services and information that are not always accessible and where they are most needed - in the right place (Schroeter \& Foth, 2009), but also suggests questions due to the organising and disciplining nature of these media and their effects on the protection of citizens' privacy and freedom (Parmett, 2017).

This analysis, from the perspective of mobile devices, in which the user is perceived as a prosumer of information, identifies "recombinatory" characteristics, and even suggests a new paradigm - in which the capabilities of the computer are "transferred" to the user ${ }^{10}$, by considering the ubiquity of its presence, in particular of electronic surveillance systems, which places into question the balance of forces in that relationship. It is

\footnotetext{
${ }^{8}$ Created from the concept of "augmented reality" as opposed to "virtual reality" which presupposes an alternative, simulated space, while the former exists in real space.

${ }_{9}^{9}$ Manovich maintains that, in practice, there is a discontinuity, since, for example, surveillance cameras do not monitor all spaces and the network signals are weaker or even non-existent in certain areas.

${ }^{10}$ Amin points out that, in this perspective, "increased space" would relate to Douglas Engelbart's dream of computer increasement of human intellect (Amin, 2002, p. 225).
} 
possible to relate the vision of a continuous digital space that covers everything and impregnates information in different senses to Amin's perspective of"deterritorialisation" or, more properly, of "reterritorialisation" of social organisations. A new geography that transforms the network of interactions and meanings. An invisible fabric in constant recombination, which combines physical and digital realities, making it increasingly difficult to perceive the seams between them.

\section{HYPERLOCALISATION: NEW FLÂNEURS OR OLD PRISONERS?}

Regardless of technological degree of sophistication, experience is always dependent upon place. It was initially argued in this article that mobile devices enable individuals to redefine the sense of place and social relations themselves. The informational mobility occurs at the interface between the electronic space and the physical space. It is in the tension between the borders of different territories that a certain place conquers its distinctive traits (cultural, social, etc.) and thus acquires identity (Lemos, 2009). Physical and informational mobility produce places and the media - by making it possible to create forms of knowledge and localised experience - help us to expand our spatio-temporal perception, producing new "senses of place".

According to Lemos (2009), digital media create new informational, socially differentiated territories and, thus, new senses of place, stimulating a culture of nomadism. In the opinion of Lemos, somewhat paradoxically, the development of industrial and capitalist societies sought to "dominate" the human tendency towards nomadism, through laws or institutions that promote sedentarism. But globalisation, that also results from this same evolution, questions these frontiers and expands the possibilities of physical and informational displacement. Cyberculture thus proposes a new "virtual" nomadism. Email addresses and mobile phone numbers are the first "non-territorial addresses" (Attali quoted in Lemos, 2009, p.30). The new nomad is the person who "goes through the points, looking for what is between them and creating paths, looking for informational territories, places of connection" (Lemos, 2009, p. 31).

This interpretation refers to the figure of the flâneur, an emblematic character of the $19^{\text {th }}$ century Paris. In 1863 , Baudelaire described him not simply as a hobo, but as an "artist", an observer of all the intricacies of urban life who draws inspiration from it as a source of creation (Kramer \& Short, 2011). For Baudelaire, the flâneur is "the painter of the circumstantial and all that it suggests of eternal" $(1996$, p. 11), searching small ephemeral details of modern life. In the $20^{\text {th }}$ century, Walter Benjamin used the same figure to criticise modernity (Benjamin, 2000).

For Benjamin, as in Baudelaire, the flâneur strolls through the city with no clear purpose, observing the urban architecture and the crowd without engaging them, concentrating only on the pleasure of looking. In Benjamin's epoch, the flâneur was already in extinction. Benjamin views the flâneur as a construct which enables him to describe and criticise the progress associated with the development of capitalism and argues that his disappearance is linked to the triumph of capitalism. He is therefore presented as a 
symbol of the resistance to modernity, materialism and artificial acceleration. The flâneur is a wanderer who dissociates himself from time and space, defining his own itinerary and relation with the places he visits, despising material goods and focusing on gaze and reflection (Birkerts, 1982). He is meant to be a "perpetual outsider" who reflects the world without being absorbed (Simon, 2006, p. 63), observing the spectacle of consumerism but not allowing himself to be immersed uncritically (Kramer \& Short, 2011).

According to Kramer and Short (2011), today we may find this figure associated with artistic and social responses to massive urbanisation, in which flânerie emerges as an ideal of critical exploration of urban environments. Through the walk ("strolling" as a way to observe the vitality of city life), these exploratory approaches combine research, leisure and artistic creation and combine artists, observers and public in the same community of participants. According to the authors, globalisation favours yet another form of flânerie. It is the global nomad, the "nomad flâneur" (Kramer \& Short, 2011, p. 337) who moves from city to city along the global communications and transport network. As an example of this global nomadism, they identify precisely the circuit of biennials and art fairs in global cities. The contemporary flâneur would thus be more cosmopolitan. However, the authors point out that the commodification of cities tends to transform his random strolling into "prescribed routes of the consumer of history, goods, ideas and experiences" (Kramer \& Short, p. 338). For this reason, they argue that the experience of the Baudelairean flâneur is still possible today, mainly in the cities of developing countries.

If digital media play a role in the construction of personalised space-time experiences in relation to which we can position ourselves as participant observers (Fazel, 2018), it is indeed possible to argue that the new practices favoured by digital technology in the $21^{\text {st }}$ century can be analysed from the concept of flânerie transposed to the context of cyberspace (Fazel, 2018; Lemos, 2009; Simon, 2006). The cyberflâneur, like Baudelaire's flâneur, maintains "loose" relationships with spatio-temporal contexts, in order to remain "mobile" (Simon, 2006).

This seems to be the case if we consider an experiment conducted by Bansky in an art residence in New York". Nadav Hochman, Lev Manovich and Mehrdad Yazdani (2014) analysed this experience, focusing on how hyperlocalisation - understood here as the association between a given information and a specific time and place, although the authors note the lack of consensus in this definition - through social media, influences the perception of localised events. From the observation of 28.419 photographs tagged and shared on Instagram, three characteristics of hyperlocal social media were identified: fragmentation, temporalisation and nomadicity. Fragmentation considering that hyperlocalisation converts a place into an endless number of perspectives that do not give rise to a single sense of place but to several personal senses. The authors consider that the hyperlocal experience through social media is not spatial (since by going through their representations, we do not visit the actual places). But it is to some extent temporal,

\footnotetext{
"Better out than in" residency, held in October 2013, in which the graffiti artist performed almost daily a work in a different place of the city, placing a photo of it in Instagram and asking his followers to locate and photograph it. The result, according to the authors, was a series of real and virtual events dispersed, observing each other (Hochman \& Manovich,2013, p. 4).
} 
when focused on the "distance" between different representations of the same place. It is also temporal because hyperlocal experiences are experienced temporarily, not constituting a map, but an itinerary, that is configured in time. This perspective stands in line with that of Harvey (1999), Giddens (2002) or Castells (2010), who, as we have seen, identify changes in the space-time relationship in the same direction, as a result of technological evolution. Allowing the construction of itineraries, more than maps, the hyperlocal representations can be considered to be nomadic, in the sense that the narrative of the place is held through different routes. Hochman, Manovich and Yazdani (2014) assumed that the images, that were geographically and temporally tagged and shared through social media, correspond to the spirit of the artistic avant-garde of the late 1960s. This movement proclaimed the site-specific artwork, in which each artistic object only exists in a given space-time context. It arose in opposition to Modernism, which perceived works of art as being independent of the context, maintaining their characteristics irrespective of their location.

Hochman, Manovich and Yazdani (2014) classify the former artistic tendency as "native" and the latter as "nomadic". But the way that information is shared via the Internet assumes both opposite tendencies: it is as much annotated and temporal and geographically classified, as it is organised without any relationship to its origin (as in Google Image Search). The results led the authors to conclude that, in the specific experience analysed, if the option for labelled image and focus on the physical location corresponds to the aspirations of the artistic avant-garde, the use of social media also incorporated some "nomadic modernist understanding" (Hochman, Manovich \& Yazdani, p. 9). This occurred because they were shared by users in different contexts and not only in their original location, corresponding to the loose relationship that, according to Simon (2006), the cyberflâneur maintains with the different spatio-temporal contexts.

Digital media also confront us with power and control issues. While, on the one hand, the aforementioned malleability permits a certain freedom and "vagrancy" that is characteristic of flânerie, on the other hand, the dematerialisation of culture and the uploading of all information to cyberspace - and in this era of geolocalisation and the "internet of things", also the opposite process, downloading from cyberspace (Lemos, 2009) - seem to correspond to mechanisms of control that are closer to Foucault's panoptic device (1978) than to Baudelaire's romantic archetype. Research suggests that the dimension of social criticism inherent to the figure of the flâneur can be identified in movements of resistance to the aforementioned control, through technology itself.

This is the case in the study developed by Mark Shepard (2009) in which he analysed the possible political and sociocultural implications of computational ubiquity, especially in an urban context. The "sentient city", according to Shepard, is one that is able to hear and feel and that is capable of actively reacting to what happens around it. But the contextual information to which it has access is relevant. Knowing where a person is, when and with whom, his/her purchase history, mobility pattern, etc., enables sentient systems to accurately predict behaviour. Shepard refers with concern to projects such as MIT Serendipity that uses Bluetooth technology to identify possible matches of interests 
between people. The project's goal is to increase business productivity by facilitating the "encounter" of colleagues with common interests or complementary needs, who would be alerted about each other's matched interests or needs, which is necessarily associated with a certain degree of lack of control by the people involved in access to their personal data $^{12}$. Another MIT project, Gaydar, analysed Facebook data to see whether people were aware of all the personal information about themselves that they revealed, for example, simply in terms of their network of friends. According to Shepard, this study illustrates how information revealed in a certain context can easily be used to interpret information in another unforeseen context. Consumer databases and localisation systems constitute citizen monitoring mechanisms. These are pervasive systems that organisations seek to make invisible and "mundane" (Mann, Nolan \& Wellman, 2003, p. 2).

On the one hand, traffic monitoring systems, based on "intelligent" control (Shepard, 2009, p. 1) such as traffic lights, for example, are apparently benign applications of such monitoring. Systems capable of correlating and anticipating human behaviour can facilitate the organisation of everyday life. But refinement of these systems fuels debate about the ubiquity of surveillance systems which are increasingly digital, in particular because less harmless uses may include security devices, such as those implemented in London or New York in the wake of the terrorist attacks, including surveillance cameras and automatic number plate recognition systems. Shepard questions the implications of these pervasive safety systems, in particular in the case of system errors. What guarantees of privacy and autonomy does the citizen have in this case? ${ }^{13}$

In this scenario, Shepard questions which other artistic practices may be conceived, besides the use of location-tracking media to explore urban spaces with more or less originality. Shepard asks what role "might artists, architects and designers play in shaping how we inhabit the near-future Sentient City?" (2009, p. 5).

A possible answer may be the one offered by Steve Mann, Jason Nolan and Barry Wellman (2003), who suggest strategies of "sousveillance" as a way of problematising surveillance and our acquiescence to it. This is achieved through panoptic technologies that enable individuals to observe those who watch over them ${ }^{14}$. With this objective, the authors propose a series of "reflective" performances (in which the roles of watcher/watched are changed) in order to question the pervasiveness of surveillance cameras and thus to raise awareness of the "disempowering nature of surveillance, its overwhelming presence in western societies, and the complacency of all participants towards this presence" (2003, p. 347). In this same logic of awareness, Shepard (2009) presents the Sentient City Survival Kit, a research design experiment suggesting a set of surviving artefacts for the future sentient city. Inspired by the practices of archaeology, it is intended to "rebuild" a world from artefacts not from the past but from the near future

\footnotetext{
${ }^{12}$ In addition, as the author refers, the term serendipity refers to the process of finding something when looking for something different, precisely the opposite of what happens in the project described

${ }^{13}$ Edward Snowden's revelations have shown precisely this lack of guarantees.

14 The authors cite the example of an American citizen who filmed the moment when policemen beat Rodney King, which facilitated the trial of those responsible and a public discussion about the brutality of the police forces.
} 
and thereby stimulate the process of imagining and promoting the discussion about the future city we really want.

From the same resistance logic proposed by Mann et al. (2003) and positioning itself as an invitation to a certain dilettantism, GPS Serendipitor is one of the artefacts proposed by Shepard (2009). It is a navigation software that suggests alternative routes to travel the distance between two points, itineraries that the user did not previously cover. The assumption is that in the future city finding the path between two points will not be the main problem. What may be more difficult is to be aware of what happens along the way. It seems to us undeniable that promoting nomadic escapism in the future sentient and controlling city also involves resisting it, cultivating a certain flânerie, in the old moulds of the $19^{\text {th }}$ century figure. But, Shepard asks, "what are the implications of a society that needs to download an application for serendipity?" (Shepard, 2009, p. 6).

In short, we could conclude that the digital flâneur, like the contemporary urban flâneur, may assume two configurations: a more individualistic and experiential one, if we confine ourselves to the possibilities offered by hyperlocalisation in the definition of personal itineraries, and another more conscious and critical, if we consider the approaches oriented towards awareness and resistance to the pervasiveness of control and surveillance systems.

\section{Conclusion}

In this text, the authors assume that the evolution of digital media alters the relationship that humans weave with space and time, in particular favouring the perception of elimination of space and acceleration of time. Based on the concept of space-time compression (Harvey, 1999), the authors briefly presented the perspectives that identify a determinant role of technology, juxtaposing them with others that emphasise the role of social change to explain that transformation.

It seems to us that it is relevant to analyse the relationship between the four dimensions considered herein - time, space, technology and society, especially in view of the inevitability of permanent social and technological evolution. In any case, regardless of whether we understand it as the main cause or a simple tool, the role of digital technology and the possibilities offered by it are unavoidable. Digital technology increasingly permeates all dimensions of social life, making, as Manovich (2006) says, "cyberspace" no longer an alternative (utopian or dystopian) world of the beginnings of computing technology but rather the very norm, with a relevant impact on the perception and experience of space-time. Castells even uses the concept of "timeless cyberspace" (2010) to describe the spatio-temporal experience in networked societies. The concept of "reterritorialisation" of social organisation seems to us to reflect what will be a new geography in constant recombination, which unites physical and digital realities.

The invocation of the flâneur relates to aspects of this new context that we associate with a certain cyber flânerie. This is because it is a context that essentially favours the definition of personal itineraries and the maintenance of fluid relations with the different 
space-time contexts covered by the citizen/cybernaut. The analysis of Bansky's artistic experience related to hyperlocalisation corroborates this perspective, in a way, by identifying mechanisms of fragmentation, temporalisation and nomadicity/nativism in the use of spaces.

In another perspective, the pervasiveness of digital media seems to contradict this possibility of "wandering", as demonstrated by Manovich's (2006) analysis of "augmented spaces". If, on the one hand, the existence of a "dataspace" that fills the entire physical space makes it open to manipulation and individual reconfiguration (Manovich, 2013), on the other hand, the ubiquity of electronic surveillance systems seems to counter this autonomy. This is also the concern of Shepard (2009) and Mann et al. (2003) when they propose reflections based on artifacts and artistic performances that may encourage the questioning and awareness of the ubiquity of digital media and their role as instruments of control and interference in privacy and individual autonomy. In this sense, these are also perspectives and strategies that cultivate the spirit of the flâneur who resists, moving away from the crowd, identifying and seeking to safeguard that which is progressively lost as a result of "progress".

Translations/revision: Sombra Chinesa Unipessoal Lda.

\section{REFERENCES}

Amin, A. (2002). Spatialities of globalisation. Environment and Planning A, 34(3), 385-399. https://doi. org/10.1068/a3439

Antonsich, M. (2011). Grounding theories of place and globalisation. Tijdschrift Voor Economische En Sociale Geografie, 102(3), 331-345.

Baudelaire, C. (1996). Sobre a modernidade. São Paulo: Editora Paz e terra.

Benjamin, W. (2000). A modernidade e os modernos. Rio de Janeiro. Tempo Brasileiro.

Birkerts, S. (2018). Walter Benjamin, Flâneur: a flanerie. The lowa Review, 13(3-4), 164-179. https://doi. org/10.17077/0021-065X.2961

Castells, M. (2010). The rise of the network society. Massachusetts: Blackwell Publishing. https://doi. org/10.2307/125209

Dourish, P. \& Bell, G. (2007). The infrastructure of experience and the experience of infrastructure: meaning and structure in everyday encounters with space. Environment and Planning B: Planning and Design, 34(3), 414-430. https://doi.org/10.1068/b32035t

Fazel, M. (2018). Live montage in mediated urban-experience: Between media and architecture. In Q. M. Troiani \& I. Zamanm (Eds.), Transdisciplinary urbanism and culture - From pedagogy to praxis (pp. 89-97). Urban Book Series. United Kingdom: Springer. https://doi.org/10.1007/978-3-319-55855-4_8

Foucault, M. (1978). Discipline and punish. The birth of the prison. New York: Pantheon Books. 
Georgalou, M. (2015). Placemaking and place identity in social media. In I. Theona \& D. Charitos (Eds.), Hybrid city 2015- Data to the people - Proceedings of the 3rd International Biennal Conference (pp. 361-370). Athens: University Research Institute of Applied Communication. https://doi. org/10.1145/2505494.2505505

Gere, C. (2008). Digital culture. London: Reaktion Books.

Giddens, A. (2002). Modernidade e identidade. Rio de Janeiro: Jorge Zahar Editor

Graham, S. (1998). The end of geography or the explosion of place? Conceptualizing space, place and information technology. Progress in Human Geography, 22(2), 165-185. https://doi. org/10.1191/030913298671334137

Harvey, D. (1989). The condition of postmodernity: an enquiry into the origins of social change. Oxford: Blackwell Publishers.

Harvey, D. (2015). O espaço como palavra-chave. Em Pauta, 35(13), 126-152.

Heyd, T. \& Honkanen, M. (2015). From Naija to Chitown: the new african diaspora and digital representations of place. Discourse, Context and Media, 9, 14-23. https://doi.org/10.1016/j.dcm.2015.06.001

Hochman, N., \& Manovich, L. (2013). Zooming into an Instagram City: reading the local through social media. First Monday, 18(7). Retrieved from http://revuecaptures.org/référence-bibliographique/ zooming-instagram-city-reading-local-through-social-media

Hochman, N., Manovich, L. \& Yazdani, M. (2014). On hyper-locality: performances of place in social media. In Proceedings of 2014 International AAAI Conference on Weblogs and Social Media (ICWSM). Retrieved from http://manovich.net/index.php/projects/on-hyper-locality-performances-of-place-in-social-media

Innis, H. A. (1950). Empire and communications. Toronto: Toronto University Press.

Kim, Y. (2016). Diasporic daughters and digital media: 'willing to go anywhere for a while'. Cultural Studies, 30(3), 532-547. https://doi.org/10.1080/09502386.2015.1113638

Kramer, K. \& Short, J. R. (2011). Flânerie and the globalizing city. City: analysis of urban trends, culture, theory, policy, action, 15(3-4), 322-342. https://doi.org/10.1080/13604813.2011.595100

Latour, B. (1996). Article on actor-network theory. A few clarifications plus more than a few complications. Soziale Welt, 25(3), 1-16,369-381. https://doi.org/10.2307/40878163

Lemos, A. (2016). Cultura da mobilidade. Revista Famecos, 16(40), 28-35. https://doi. org/10.15448/1980-3729.2009.40.6314

Löw, M. (2008). O spatial turn: para uma sociologia do espaço. Revista Tempo Social, 25(2), 17-34. https://doi. org/10.1590/S0103-20702013000200002

Mann, S., Nolan, J. \& Wellman, B. (2003). Sousveillance: inventing and using wearable computing devices for data collection in surveillance environments. Surveillance and Society, 1(3), 331-355. https://doi. org/10.24908/ss.v1i3.3344

Manovich, L. (2006). The poetics of augmented space. Visual Communication, 5(2), 219-240. https://doi. org/10.1177/1470357206065527

Marx, K. (1887). Capital: a critique of political economy. Volume I. Retrieved from https://www.marxists.org/ archive/marx/works/download/pdf/Capital-Volume-I.pdf 
Massey, D. (1991, junho). A global sense of space. Marxism Today, 24-29. Retrieved from http://www.unz.org/ Pub/MarxismToday-1991jun-00024

Mcluhan, M. (1969). Os meios de comunicação como extensões do homem. Nova lorque: McGraw-Hill Book Company. Retrieved from https://books.google.pt/books?id=wFvBeUıjVwIC\&lpg=PAg\&ots=K2vQDYffn 7\&dq=marshall\%2omcluhan\&lr\&hl=pt-PT\&pg=PA6\#v=onepage\&q=marshall\%2omcluhan\&f=false

Parmett, H. M. (2017). Space. In L. Ouellette \& J. Gray (Eds.), Key words for Media Studies (pp. 181-183). New York: NYU Press.

Rosa, H. (2013). Social acceleration. A new theory of modernity (new directions in critical theory) - Hartmut Rosa. New York: Columbia University Press.

Schroeter, R. \& Foth, M. (2009). Discussions in space. In OZCHI 2009: 21st Annual Conference of the Australian Computer-Human Interaction Special Interest Group (CHISIG) of the Human Factors and Ergonomics Society of Australia (HFESA), Nov 23-27, Melbourne. https://doi.org/10.1145/1738826.1738903

Sharma, S. (2014). In the meantime: temporality and cultural politics. Durham, NC: Duke University Press. https://doi.org/10.1215/9780822378334

Shepard, M. (2009). Sentient city survival kit: archaeology of the near future. UC Irvine: Digital Arts and Culture 2009. Retrieved from https://escholarship.org/uc/item/4zpoc4x2

Simon, B. (2006). Beyond cyberspatial flâneurie: On the analytic potential of living with digital games. Games and Culture, 1(1), 62-67. https://doi.org/10.1177/1555412005281789

Sora, C., Jordà, S. \& Codina, L. (2017). Chasing real-time interaction in new media: towards a new theoretical approach and definition. Digital Creativity, 28(3), 196-205. https://doi.org/10.1080/14626268.2017.13553 23

Subtil, F. (2014). Harold A. Innis. O viés da comunicação. Comunicação Pública [Online], 8(13). Retrieved from http://journals.openedition.org/cp/525

Virilio, P. (1989). Esthétique de la disparition. Paris: Éditions Galilée.

Virilio, P. (2000). Cibermundo: a política do pior. Lisboa: Editorial Teorema.

\section{BIOGRAPHICAL NOTES}

Ivone Neiva Santos holds a master in sociology by the University of Oporto, Faculdade de Letras. She is also researcher working in the project "CHIC Science-Cooperative Holistic view on Internet and Content". She has previous experience in research projects in the areas of communication of science and digital journalism, with relevant experience concerning educational and business sectors. Presently she is doctoral student in digital media PhD program at the University of Oporto. Among other areas of interest, she works on the relationship between technological development, cultural practices and social dynamics.

ORCID: https://orcid.org/oooo-0oo2-5466-5572

Email: ivoneneivasantos@gmail.com

Adress: Faculdade de Letras da Universidade do Porto, Via Panorâmica, s/n , 4150564 Porto 
José Azevedo is associate Professor at the University of Oporto. He was Fulbright Scholar at the University of Texas, Austin (2001) and Visitor professor at the University of North Carolina - Chapel Hill (2004) supported by the Gulbenkian Foundation and the Luso-American Foundation. He coordinated several international projects, including about digital media for the teaching of climate change. He participates in the coordination of several scientific journals and is member of scholarships and projects evaluation panels (FCT, UT Austin Portugal, among others).

ORCID: https://orcid.org/0000-0002-6738-1827

Email: azevedo@letras.up.pt

Adress: Faculdade de Letras da Universidade do Porto, Via Panorâmica, s/n , 4150564 Porto

* Submitted: $24 / 11 / 2018$

* Accepted: 24/12/2019 